\title{
Virus-induced gene silencing reveals the involvement of ethylene-, salicylic acid- and mitogen-activated protein kinase-related defense pathways in the resistance of tomato to bacterial wilt
}

\author{
Yong-Yi Chen ${ }^{a}{ }^{\dagger}$, Yu-Mei Lin ${ }^{a}{ }^{\dagger}$, To-Chun Chao ${ }^{a}$, Jaw-Fen Wang ${ }^{b}$, An-Chi Liu ${ }^{a}$, Fang-I Ho ${ }^{b}$ and \\ Chiu-Ping Cheng ${ }^{\mathrm{a}, *}$ \\ ${ }^{a}$ Graduate Institute of Plant Biology and Department of Life Science, National Taiwan University, No. 1, Sec. 4, Roosevelt Road, Taipei, Taiwan 106, \\ Republic of China \\ ${ }^{\text {b} A V R D C ~-~ T h e ~ W o r l d ~ V e g e t a b l e ~ C e n t e r, ~ P O ~ B o x ~ 42, ~ S h a n h u a, ~ T a i n a n, ~ T a i w a n ~ 741, ~ R e p u b l i c ~ o f ~ C h i n a ~}$
}

\section{Correspondence \\ *Corresponding author, \\ e-mail: chiupingcheng@ntu.edu.tw}

Received 8 January 2009; revised 12

February 2009

doi: 10.1111/j.1399-3054.2009.01226.x

\begin{abstract}
Bacterial wilt (BW), caused by Ralstonia solanacearum, is a devastating vascular disease of tomato worldwide. However, information on tomato's defense mechanism against infection by this soil-borne bacterium is limited. In this study, virus-induced gene silencing (VIGS) was employed to decipher signaling pathways involved in the resistance of tomato to this pathogen. Defined sequence fragments derived from a group of genes known or predicted to be involved in ethylene (ET) and salicylic acid (SA) signaling transduction pathways and mitogen-activated protein kinase (MAPK) cascades were subjected to VIGS in 'Hawaii 7996', a tomato cultivar with stable resistance to $\mathrm{BW}$, and their effect on resistance was determined. The results indicated that silencing of ACO1/3, EIN2, ERF3, NPR1, TGA2.2, TGA1a, MKK2, MPK1/2 and MPK3 caused significant increase in bacterial proliferation in stembases and/or mid-stems. Partial wilting symptoms appeared on plants in which TGA2.2, TGA2.1a, MKK2 and MPK1/2 were silenced. These results suggested that ET-, SA- and MAPK-related defense signaling pathways are involved in the resistance of tomato to BW. This is the first report elucidating the multiple layers of defense governing the resistance of tomato to BW. The results are discussed to enlighten an important and complex interaction between tomato and a soil-borne vascular pathogen.
\end{abstract}

\section{Introduction}

Plants have developed subtle mechanisms to rapidly sense and fend off pest and pathogen attacks. The key roles various hormones and signaling pathways play

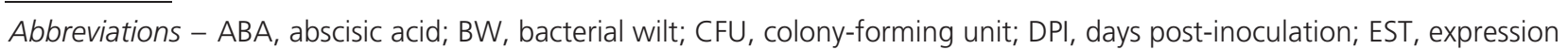
sequence tag; ET, ethylene; H7996, Hawaii 7996; JA, jasmonic acid; LR recombination, recombination of attL sites with attR sites; MAPK, mitogen-activated protein kinase; MAPKKK, MAPK kinase kinase; $R$ gene, RESISTANCE gene; RT-PCR, reverse transcriptase-PCR; SA, salicylic acid; TRV, tobacco rattle virus; VIGS, virus-induced gene silencing.
}

tThese authors contributed equally to this work.

in plant defense mechanisms have been demonstrated. Major defense signaling pathways that have been intensively studied include jasmonic acid (JA), ethylene $(\mathrm{ET})$, salicylic acid (SA) and mitogen-activated protein kinase (MAPK) cascades (Koornneef and Pieterse 2008).

\footnotetext{
Physiol. Plant. 2009
} 
In nature, these pathways are not completely separate. To minimize ineffective defenses and achieve the proper response to specific stress, plants need to temporally and spatially integrate and orchestrate various defense signaling pathways. Certain cross talks and regulation, both positive and negative, occur between these pathways in plants (Bostock 2005, Koornneef and Pieterse 2008).

Bacterial wilt (BW), caused by Ralstonia solanacearum, is a complex and serious soil-borne vascular disease affecting tomato and many other crops worldwide. Because of the lack of effective chemical controls, the soil-borne nature of the pathogen and the wide range of its hosts, host resistance is the main strategy for control (Scott et al. 2005). However, the diverse strains of $R$. solanacearum make the development of stable resistance a challenge. A few tomato cultivars have displayed stable resistance over locations or against various R. solanacearum strains (Wang et al. 1998) with cultivar 'Hawaii 7996' (H7996), the most studied. Although several quantitative trait loci associated with resistance in H7996 have been mapped (Carmeille et al. 2006, Wang et al. 2000), no information on their identity and possible function is currently available. It should be noted that none of the resistance to BW in tomato is immune. Latent infections occur in resistance cultivars of tomato (Prior et al. 1994). The visual wilting symptom caused by $R$. solanacerum in tomato is correlated with the pathogen distribution and bacterial density in the stem. A high bacterial density at the level of $10^{9}-10^{10}$ $\mathrm{CFU} \mathrm{g}^{-1}$ plant tissue is required for the appearance of wilting (Grimault et al. 1994, Wang and Lin 2005). In $\mathrm{H} 7996$, R. solanacearum is largely confined to theprimary xylem and is a poor colonizer in this host (Nakaho et al. 2004). It has been hypothesized that polyphenols produced by H7996 might restrict pathogen spreading through the root (Vasse et al. 2005). Information about the resistance mechanism in $\mathrm{H} 7996$ is limited.

Current knowledge about natural plant defense mechanisms against $R$. solanacearum is mostly derived from the studies with Arabidopsis. It has been demonstrated that JA-, ET- and abscisic acid (ABA)-related defense signaling pathways are involved in Arabidopsis response to the bacterium's attack (Deslandes et al. 2002, Hernandez-Blanco et al. 2007, Hirsch et al. 2002). Additionally, the only RESISTANCE gene ( $R$ gene) against the pathogen isolated to date is Arabidopsis RRS1, which recognizes an avirulence protein of $R$. solanacearum strain GMI1000 (Deslandes et al. 2002, 2003, Lahaye 2004). The information gained from the Arabidopsis system cannot be applied directly to the tomato system, as several studies have revealed that the molecular mechanisms and response of solanaceous plants to $R$. solanacearum or other pathogens could be different from those in Arabidopsis (Lin et al. 2008a, Robatzek et al. 2007, Wei et al. 2007). Thus, gaining insight into the natural defense mechanism of tomato to BW is crucial; the knowledge would contribute to breeding for more stable resistance as well as overall disease control.

Virus-induced gene silencing (VIGS) has been used in high-throughput reverse and forward genetic screens to study roles ofgenes in various aspects of plant function (Burch-Smith et al. 2004). Among the vectors developed for VIGS, the tobacco rattle virus (TRV)-based vector is the most commonly used in a range of plant species, particularly in Solanaceae (Burch-Smith et al. 2004). However, VIGS has not been used to study interactions involving plant and soil-borne vascular pathogens in a systematic manner.

In this study, we employed TRV-based VIGS, combined with an inoculation system mimicking natural infection developed previously (our unpublished data), to explore the role of ET-, SA- and MAPK-related defense signaling pathways in the molecularmechanisms governing BW resistance in tomato cultivar H7996. The results suggest that tomato fends off the bacterium by multiple layers of defense mechanisms, which involve ET-, SA- and MAPK-related defense signaling pathways.

\section{Materials and methods}

\section{Plant material and growth conditions}

Tomato (Solanum lycopersicum) cultivars used in this study included H7996 (BW resistant) and L390 (BW susceptible). After soaking in water with gentle shaking for 2 days, the germinated seeds were sown in 2.5inch pots containing potting mixture. Plants were grown in a growth chamber with $25^{\circ} \mathrm{C}$ day temperature and $20^{\circ} \mathrm{C}$ night temperature, a $12 \mathrm{~h}$ light period and relative humidity of $75 \%$. Nine to ten days after sowing in soil, when cotyledons were fully expanded, plants were subjected to VIGS tests by inoculation with Agrobacterium suspensions (see below).

\section{Plasmid constructs and Agrobacterium tumefaciens strains}

pTRV1 and pTRV2 derivatives were used as the vectors for gene silencing (Liu et al. 2002). Fragments of ACO1, ACO5, CTR1, EIN2, ERF3, TSRF1, NPR1, TGA2.2, TGA1a, MP3Ka, MKK2, MKK3, MKK4, MPK1, MPK3 and MPK4 were obtained by reverse transcriptasepolymerase chain reaction (RT-PCR) from tomato H7996 complementary DNA using primers listed in 
Appendix S1. The PCR product was cloned into the $\mathrm{pCR}^{\circledR}$ 8/GW/TOPO ${ }^{\circledR}$ vector, and then recombined into a pTRV2 vector, pYL279, by carrying out an LR recombination reaction using the Gateway ${ }^{\circledR}$ system (Invitrogen Co., Carlsbad, CA). pYL279-m, a modified pTRV2 empty vector, in which the selectable CHLORAMPHENICOL RESISTANCE gene and the counter-selectable ccdB gene had been removed, was constructed via an $L R$ recombination reaction with the empty $\mathrm{pCR}{ }^{\circledR}$ 8/GW/TOPO ${ }^{\circledR}$ vector. This was used as the empty vector control. The pYL279 recombinant constructs obtained were electroporated into cells of A. tumefaciens GV3101 by a MicroPulser (Bio-Rad, Hercules, CA). The resultant Agrobacterium strains were used in the indicated VIGS experiments.

\section{Virus infection by Agrobacterium-mediated infiltration}

A. tumefaciens GV3101 strains carrying each TRV derivative were grown at $28{ }^{\circ} \mathrm{C}$ in the selection YEP medium $(0.5 \%$ peptone, $0.5 \%$ yeast extract and $1 \%$ sodium chloride) containing appropriate antibiotics, and bacterial suspensions $\left(\mathrm{OD}_{600}=2\right)$ were prepared for infiltration on cotyledons following a similar procedure as described in Liu et al. (2002). Agroinfiltrated plants were maintained at $22^{\circ} \mathrm{C}$ in a growth chamber with a $12 \mathrm{~h}$ light period for the indicated periods of time.

\section{Assessment of plant response to the infection of R. solanacearum}

Inoculation of $R$. solanacearum on tomato plants was conducted as described in Lin et al. (2008a); the procedure is outlined briefly here. A suspension of strain Pss4 (phylotype I, race 1, biovar 3) was prepared to give an $\mathrm{OD}_{600}$ of 0.6 and used to challenge plants. Ten days after agroinfiltration of the VIGS constructs, the Pss4 suspension was poured over the pot soil surface. A lower inoculum dose $\left(5 \times 10^{5} \mathrm{CFU} \mathrm{m^{-1 } )}\right.$ was used when gene-silencing experiments were carried out in L390 to determine the role of CTR 1 in tomato susceptibility to $R$. solanacearum. The percentages of wilted plants were recorded 5 days after inoculation. Afterward, bacterial density in tomato plants was determined by taking surface-sterilized segments (about $1 \mathrm{~cm}$ in length) of stembase and mid-stem of eachplant. The stem segments were weighed, crushed in $1 \mathrm{ml}$ sterilized water, diluted and plated on SM1 medium. The numberof bacterial colonies developed was recorded 2 days after incubation at $28^{\circ} \mathrm{C}$. For the assay of each gene, 6-12 plants were used in each experiment, and at least three independent experiments were performed. Pair-wise mean comparisons of bacterial density at the stembases and mid-stems were conducted between TRV-infected and silenced plants with Student's $t$-test.

\section{Semiquantitative RT-PCR analysis}

Total RNA was isolated from the indicated tissues of plants with the RNeasy Plant Mini Kit (Qiagen, Hilden, Germany). Fiveto ten micrograms of total RNA was treated with RNase-free DNase I (Promega, Madison, WI) followed by phenol/chloroform extraction to remove DNase. The first-strand cDNA was synthesized from $1 \mu \mathrm{g}$ total RNA with oligo (dT) primer and AMV reverse transcriptase (Promega). Semiquantitative RT-PCR was performed as described (Ekengren et al. 2003). Primers used for RT-PCR to check transcript abundance of the silenced genes are listed in Appendix S1.

\section{Results}

Silencing of genes involved in the ET signaling transduction pathway decreased resistance of H7996 to $B W$ and enhanced tolerance of $L 390$.

Defined sequence fragments (Table 1), derived from six genes (ACO1, ACO5, CTR1, EIN2, ERF3 and TSRF1) known or predicted to be involved in ET biosynthesis and signaling pathways, were amplified from H7996 and used to develop TRV constructs for VIGS tests in H7996. As revealed in Fig. $1 \mathrm{~A}$, the transcript accumulation of these targetedgenes in stembases of silenced plants was reduced at various levels. Except for ACO1 and TSRF1, cross-silencing of other genes trigged by the same fragments is unlikely to occur, as no significant sequence homology (21 continuous identical nucleotides, Thomas et al. 2001) was found between these fragments and ESTs or genes currently available in tomato sequence databases (Table 1). The transcript accumulation of ACO1 and ACO3 was significantly reduced in stembases of $A C O 1$-silenced plants, but not that of ACO4, which shares less sequence homology with ACO1 (Fig. 1A). Additionally, no apparent effects on growth and development of the silenced plants were observed 15 days after agroinfiltration, except that silencing of CTR1 led to typical epinastic phenotypes of constitutive ET response (data not shown).

To determine whether ET biosynthesis and signaling pathways are involved in the resistance of tomato to BW, gene-silenced plants were inoculated with R. solanacearum by root drenching 10 days after agroinfiltration. At this time point, VIGS efficacy had already started in roots, stembase and even in young leaves (our unpublished data). Resistance to $R$. solanacerum in tomato is usually correlated with 
Table 1. Tomato genes tested in this study and comparison of the most closely related paralogs of the test genes. Unigene numbers for tomato were taken from SGN website. Nucleotide identity indicates the overall sequence identity between the two genes. Identical length indicates the length of longest continuous stretch where the sequences are identical between the two genes. ' - ' indicates no paralog was identified in current databases. N/A, not applicable.

\begin{tabular}{|c|c|c|c|c|}
\hline $\begin{array}{l}\text { Targeted } \\
\text { tomato genes }\end{array}$ & Unigene number & $\begin{array}{l}\text { Corresponding } \\
\text { genes in tobacco } \\
\text { or Arabidopsis }\end{array}$ & Description & $\begin{array}{l}\text { Paralogs } \\
\text { [accession no., nucleotide identity } \\
\%, \text { identical length (bp)] }\end{array}$ \\
\hline \multirow[t]{2}{*}{ ACO1 } & \multirow[t]{2}{*}{ SGN-U314592 } & & $\begin{array}{l}\text { 1-aminocyclopropane-1-carboxylate } \\
\text { oxidase }\end{array}$ & \multirow[t]{2}{*}{ ACO3 (SGN-U314591, 98\%, 194) } \\
\hline & & & & \\
\hline ACO5 & \multicolumn{2}{|l|}{ SGN-U323861 } & $\begin{array}{l}\text { 1-aminocyclopropane-1-carboxylate } \\
\text { oxidase }\end{array}$ & - \\
\hline CTR1 & \multicolumn{2}{|l|}{ SGN-U316111 } & $\begin{array}{l}\text { A MAPK kinase kinase (MAPKKK) } \\
\text { involved in tomato ET signaling } \\
\text { pathway }\end{array}$ & - \\
\hline EIN2 & SGN-U319128 & AtEIN2 (AT5G03280) & $\begin{array}{l}\text { A downstream target ER-membrane } \\
\text { protein of CTR1 in Arabidopsis ET } \\
\text { signaling pathway }\end{array}$ & - \\
\hline ERF3 & SGN-U315194 & $N t E R F 3, N b C D 1$ & $\begin{array}{l}\text { A member of class II EFF, a transcriptional } \\
\text { repressor }\end{array}$ & - \\
\hline TSRF1 & SGN-U331411 & NtTSRF1 & A member of ERF sub-group B-3 & ERF1 (SGN-U320682, 88\%, 23) \\
\hline NPR1 & SGN-U320977 & AtNPR1 (At1 G64280) & $\begin{array}{l}\text { A key regulator of the SA-mediated } \\
\text { systemic acquired resistance pathway }\end{array}$ & - \\
\hline TGA2.2 & SGN-U318626 & AtTGA2.2 (At5G06950) & $\begin{array}{l}\text { Putative NPR1-interaction transcription } \\
\text { factor of the b-ZIP family }\end{array}$ & TGA-2.1 (SGN-U316694, 84\%, 23) \\
\hline TGA1a & SGN-U321979 & AtTGA1a (AT5G65210) & $\begin{array}{l}\text { Putative transcription factor with } \\
\text { DNA-binding and calmodulin-binding } \\
\text { domain }\end{array}$ & - \\
\hline$M P 3 K \alpha$ & SGN-U323157 & & MEK kinase (MAP3K $\alpha)$ & \multirow{2}{*}{-} \\
\hline MKK2 & SGN-U319074 & NtMEK2 & $\begin{array}{l}\text { A member of MAPKK involved in } \\
\text { Pto-mediated resistance in tomato }\end{array}$ & \\
\hline MKK3 & SGN-U325519 & NtMEK1 & A member of MAPKK & \multirow{2}{*}{-} \\
\hline MKK4 & SGN-U315916 & NtSIPKK & $\begin{array}{l}\text { A member of MAPKK involved in } \\
\text { Pto-mediated resistance in tomato }\end{array}$ & \\
\hline \multirow[t]{3}{*}{ MPK1 } & SGN-U316697 & NtSIPK & $\begin{array}{l}\text { A member of MAPK involved in } \\
\text { pathogen resistance, wounding, ET } \\
\text { biosynthesis, oxidative stress and } \\
\text { osmotic stress }\end{array}$ & MPK2 (NtNTF4) (SGN-U316695, 90\%, 77) \\
\hline & & & & MPK3 (SGN-U313928, 81\%, 21) \\
\hline & & & & MPK16 (SGN-U216717, 96\%, 23) \\
\hline \multirow[t]{2}{*}{ MPK3 } & SGN-U313928 & NtWIPK & $\begin{array}{l}\text { A member of MAPK involved in } \\
\text { pathogens resistance, wounding, cold, } \\
\text { salinity stress. }\end{array}$ & MPK1 (SGN-U316697, 81\%, 21) \\
\hline & & & & \multirow{3}{*}{$\begin{array}{l}\text { CDPK (SGN-U332911, 100\%; 21) } \\
\text { MPK5 (SGN-U313996, 83\%, 25) } \\
\text { MPK16 (SGN-U318101, 100\%, 24) }\end{array}$} \\
\hline \multirow[t]{2}{*}{ MPK4 } & SGN-U323634 & NtNTF6 & A member of MAPK & \\
\hline & & & & \\
\hline
\end{tabular}

the pathogen distribution and bacterial density in the stem (Grimault et al. 1994, Wang and Lin 2005). Therefore, both visual symptom development and internal bacterial density in stem parts were determined in this experiment. Tomato cultivar L390 was used as the susceptible control to confirm the success of pathogen inoculation. Under the defined experimental condition, we observed that TRV infection slightly slowed plant growth of H7996 and L390, but not their response to $R$. solanacearum (Fig. 2). L390 plants first showed wilting symptoms 3 days post-inoculation (DPI) and completely wilted $5 \mathrm{DPI}$, when the internal
$R$. solanacearum density reached at a mean greater than $10^{9} \mathrm{CFU} \mathrm{g}^{-1}$ plant tissue at the mid-stems. None of silenced H7996 plants with reduced transcript level of ET-related genes developed apparent wilting symptoms 12 days after $R$. solanacearum inoculation. Large variations were observed in the bacterial density of assayed H7996 plants. This is because of several reasons, including the high detection limit of the direct plating method ( $\geq 10^{3} \mathrm{CFU} \mathrm{g}^{-1}$ plant tissue), the effect of plant physiological status and environment on the progress of the disease and the uneven gene silencing degree over tested plants even within the same plant. 
(A)

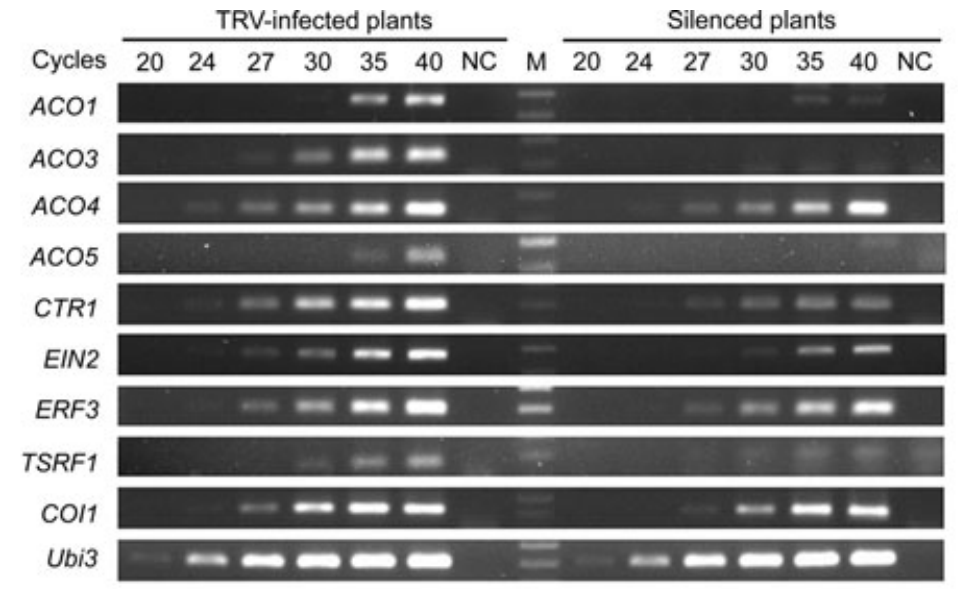

(B)

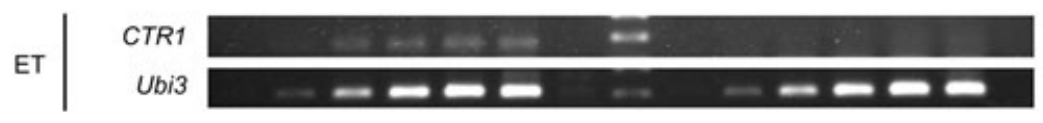

(C)

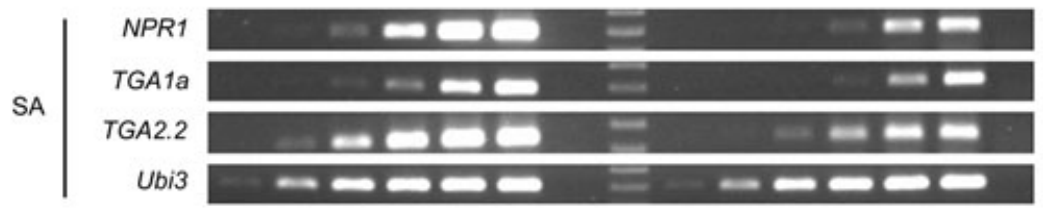

(D)

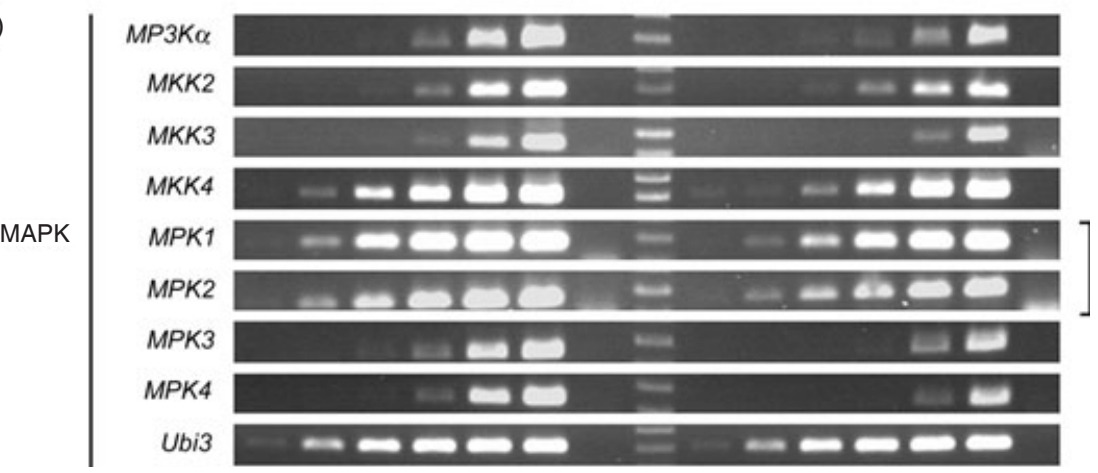

Fig. 1. VIGS-mediated reduction of specific transcript levels in tomato. BW-resistant cultivar H7996 (A, C, D) and BW-susceptible cultivar L390 (B) were agroinfiltrated with Agrobacterium tumefaciens strain GV3101 containing pTRV1 plus pTRV2 containing the targeted genes (silenced plants) or plus pTRV2 empty vector (TRV-infected plants). The targeted genes are known or predicted to be involved in ET biosynthesis and signaling pathways $(A, B), S A$ defense signaling pathway (C) and MAPK cascades (D). Silencing of genes known or predicted to be involved in ET biosynthesis and signaling pathways and genes for which we also examined a closely related paralog are shown in brackets. Ethidium bromide stained $1 \%$ agarose gels with RT-PCR products. CDNA was synthesized from total RNA isolated from pooled samples of stembases collected from two plants 15 days after agroinfiltration and used for PCR amplification using gene-specific primers (see Supporting information). Amplification of the internal control Ubi3 was performed for every gene-silenced plant with similar results (data not shown). The experiment was performed twice with similar results. PCR amplification from CDNA from a single representative sample is presented. PCR cycles are indicated on the top of the sections. Lane M indicates DNA ladder and NC indicates negative control where RNA was used as template for PCR amplification in the absence of reverse transcriptase.

Nevertheless, pair-wise $t$-test indicated that ACO1/3-, EIN2- or ERF3-silenced plants had significantly higher bacterial density in stembases and mid-stems when compared with $\mathrm{H} 7996$ plants inoculated with the empty vector (Table 2). These results indicated that silencing the ET signaling pathway decreased the resistance of tomato to BW.
Because CTR1 is known to be a negative regulator of the ET signaling pathway (Ouaked et al. 2003), the effect of silencing of this gene in response to $R$. solanacearum infection was further assessed in L390. The level of CTR1 transcript accumulation in stembases of the silenced L390 plants was reduced (Fig. 1B), leading to obvious typical phenotypes of constitutive ET response 
(a)

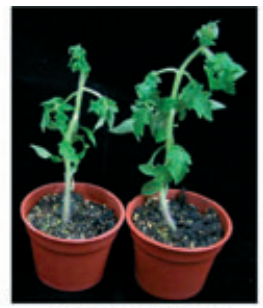

L390 (CTR1)

(b)

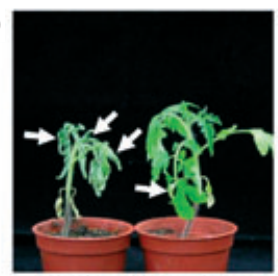

H7996 (TGA2.2)

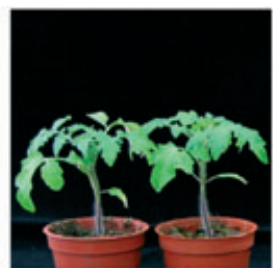

H7996 (TRV2)

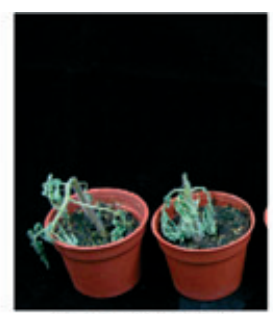

L390 (TRV2)

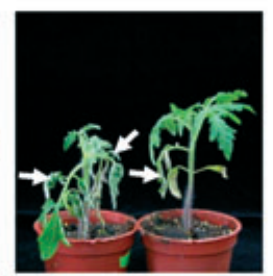

H7996 (TGA1a)

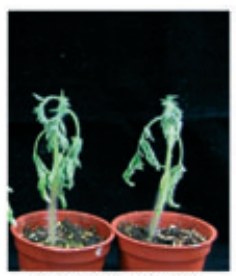

L390 (TRV2)

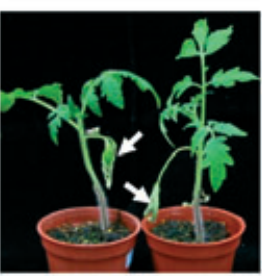

H7996 (MPK1/2)

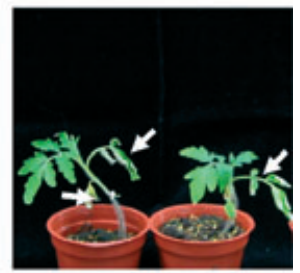

H7996 (MKK2)

Fig. 2. Wilting symptoms caused by Ralstonia solanacearum on silenced tomato plants. (A) BW-susceptible cultivar L390 plants were agroinfiltrated with Agrobacterium tumefaciens strain GV3101 containing pTRV1 plus pTRV2-CTR1 (CTR1) or the pTRV2 empty vector (TRV2); (B) BW-resistant cultivar H7996 plants were agroinfiltrated with A. tumefaciens strain GV3101 containing pTRV1 plus the pTRV2 empty vector (TRV2), pTRV2-TGA2.2 (TGA2.2), TRV2-TGA1a (TGA1a), TRV2-MPK1 (MPK1) or TRV2-MKK2 (MKK2). Ten days after agroinfiltration, the silenced plants and the control plants (those infiltrated with pTRV2 empty vector) were inoculated with $R$. solanacearum by soil drench as described in the Materials and methods. Photos were taken (A) 7 days or (B) 5 days after inoculation with $R$. solanacearum. The BW-susceptible cultivar L390 in (B) was used as a positive control for pathogen inoculation. Arrows indicate wilted leaves.

(Fig. 2A; Liu et al. 2002). When the response of L390 to R. solanacearum inoculation was evaluated $5 \mathrm{DPI}$, all of the TRV-infected control plants displayed severe wilting symptoms. Nevertheless, when CTR 1 was silenced in L390, only $50 \%$ of the plants developed partial wilting symptoms and the rest did not show any obvious wilting symptoms (Fig. 2A). These data suggested that silencing of CTR1 in BW-susceptible tomato L390, which led to constitutive ET response, resulted in reduced severity and incidence of wilting symptoms.

Silencing of genes required for the SA signaling transduction pathway reduced the resistance of tomato to $B W$.

To determine whether SA-related signaling pathway is involved in the resistance of tomato to BW, fragments derived from tomato homologs of Arabidopsis NPR1, TGA1a and TGA2.2 were prepared from and used for VIGS tests in H7996 (Table 1). As shown in Fig. 1C, the level of transcript accumulation of these genes in stembases of the silenced plants was reduced at various levels. Additionally, the silenced plants did not display apparent growth and development defects 15 days after agroinfiltration.

Upon the infection of $R$. solanacearum, silencing of TGA1a or TGA2.2 in $\mathrm{H} 7996$ resulted in a partial wilting phenotype in some, but not all, of the silenced plants 5 DPI (Fig. 2B). Additionally, much higher proportions of TGA1a- or TGA2.2-silenced plants were detected with the presence of the pathogen in stembase and mid-stems compared with the controls (Table 2). Pair-wise t-test also revealed that the silenced plants had significantly higher bacterial density in stembases and mid-stems compared with H7996 plants inoculated with the empty vector (Table 2). Although silencing of NPR1 did not cause wilting symptoms in the silenced plants, a higher proportion of colonized plants and significantly higher density of planta $R$. solanacearum were detected in midstems and stembases of the silenced plants (Table 2). Although NPR1-silenced plants harbored increased mean bacterial population comparable with that in 
Table 2. Assessment of Ralstonia solanacearum density in silenced tomato H7996 plants. Assessment was carried out 5 DPI by a method described in Materials and methods, and data were collected from at least three independent experiments. Numbers of plants with positive detection of the pathogen in stembases or mid-stems were shown by symbol ' + '. Pair-wise mean comparisons were made between TRV-infected and silenced plants with Student's $t$-test method. $P$-values are indicated in parentheses.

\begin{tabular}{|c|c|c|c|c|c|c|c|c|}
\hline \multirow{3}{*}{$\begin{array}{l}\text { Signaling } \\
\text { pathways } \\
\text { ET }\end{array}$} & \multirow{3}{*}{$\begin{array}{c}\begin{array}{c}\text { Silenced } \\
\text { genes }\end{array} \\
\text { ACO1/3 }\end{array}$} & \multirow{3}{*}{$\begin{array}{c}\text { Sample no. } \\
\text { (silenced/TRV infected) } \\
30 / 30\end{array}$} & \multicolumn{3}{|c|}{ Stembases (silenced/TRV infected) } & \multicolumn{3}{|c|}{ Mid-stems (silenced/TRV infected) } \\
\hline & & & \multirow{2}{*}{$\frac{+}{20 / 6}$} & \multicolumn{2}{|c|}{$\begin{array}{c}\log \left(\text { CFU } g^{-1} \text { plant tissue }\right) \\
(P \text {-value })\end{array}$} & \multirow{2}{*}{$\frac{+}{10 / 4}$} & \multicolumn{2}{|c|}{$\begin{array}{c}\log \left(C F U g^{-1} \text { plant tissue }\right) \\
(P \text {-value })\end{array}$} \\
\hline & & & & $4.91 / 1.40$ & $(0.0001)$ & & $2.77 / 0.93$ & $(0.0304)$ \\
\hline & ACO5 & $36 / 36$ & $12 / 11$ & $2.27 / 2.30$ & $(0.9750)$ & $4 / 3$ & $0.84 / 0.60$ & $(0.7768)$ \\
\hline & CTR1 & $24 / 24$ & $14 / 9$ & $4.35 / 2.70$ & $(0.1316)$ & $7 / 2$ & $2.10 / 0.75$ & $(0.1537)$ \\
\hline & EIN2 & $36 / 36$ & $17 / 4$ & $4.16 / 0.76$ & $(<.0001)$ & $12 / 3$ & $2.55 / 0.50$ & $(0.0039)$ \\
\hline & ERF3 & $54 / 54$ & $28 / 14$ & $3.92 / 1.81$ & $(0.0024)$ & $15 / 6$ & $2.34 / 0.75$ & (0.0078) \\
\hline & TSRF1 & $30 / 30$ & $12 / 13$ & $3.15 / 3.10$ & $(0.9641)$ & $5 / 2$ & $1.52 / 0.50$ & (0.1313) \\
\hline \multirow[t]{3}{*}{ SA/JA } & NPR1 & $42 / 42$ & $22 / 11$ & $4.45 / 1.84$ & $(0.0053)$ & $15 / 4$ & $2.63 / 0.62$ & $(0.0028)$ \\
\hline & TGA2.2 & $30 / 30$ & 23/15 & $6.56 / 3.73$ & $(0.0040)$ & 21/11 & $4.35 / 1.24$ & $(0.0017)$ \\
\hline & TGA1a & $30 / 22$ & $15 / 7$ & $3.84 / 2.27$ & $(0.1400)$ & 9/0 & $2.52 / 0.00$ & $(0.0009)$ \\
\hline \multirow[t]{7}{*}{ MAPK } & MP3K-a & 30 /30 & $12 / 13$ & $2.99 / 3.13$ & $(0.8861)$ & $2 / 7$ & $0.47 / 1.56$ & $(0.0890)$ \\
\hline & $M K K 2$ & $36 / 36$ & $22 / 14$ & $5.15 / 2.75$ & $(0.0095)$ & $15 / 7$ & $3.53 / 1.29$ & $(0.0102)$ \\
\hline & $M K K 3$ & $36 / 36$ & $13 / 11$ & $2.73 / 2.20$ & $(0.5323)$ & $5 / 5$ & $1.16 / 1.09$ & (0.9184) \\
\hline & MKK4 & $42 / 42$ & $23 / 12$ & $3.93 / 1.99$ & $(0.0120)$ & $11 / 6$ & $0.87 / 0.22$ & (0.1733) \\
\hline & MPK $1 / 2$ & $30 / 30$ & $19 / 8$ & $4.85 / 1.82$ & $(0.0013)$ & $10 / 3$ & $2.84 / 0.75$ & $(0.0189)$ \\
\hline & MPK3 & $42 / 35$ & $25 / 12$ & $4.52 / 2.26$ & $(0.0068)$ & $14 / 1$ & $2.25 / 0.21$ & $(0.0004)$ \\
\hline & MPK4 & $48 / 48$ & $21 / 16$ & $2.11 / 1.39$ & $(0.2836)$ & $8 / 6$ & $1.20 / 1.03$ & $(0.7600)$ \\
\hline
\end{tabular}

TGA1a-silenced plants, no visual wilting symptoms were observed. This is because the internal bacterial density in all plant parts of NPR1-silenced plants did not reach the level required for visual wilting. There was a large variation in internal bacterial density over and within TGA1a-silenced plants, where the bacterial density reached a sufficient level to cause wilting on a few leaves of a few plants. Together, these results indicated that silencing of the SA-related signaling pathway compromised the resistance of tomato to BW.

Silencing of genes involved in MAPK cascades caused reduction of the resistance of tomato to $B W$.

To examine roles of MAPK cascades in the resistance of tomato to BW, defined sequence fragments, derived from seven genes (MP3Ka, MKK2, MKK3, MKK4, MPK1, MPK3 and MPK4) known or predicted to be involved in MAPK pathways, were used for VIGS tests in H7996 (Table 1). Except for the case in MPK1, cross-silencing of other genes trigged by the same fragments is unlikely to occur (Table 1). Additionally, although a calciumdependent protein kinase gene (CDPK, SGN-U332911) sharing 21 continuous identical nucleotides with MPK3 was identified, its transcripts were not detected in roots, collars, stems and leaves (data not shown). As illustrated in Fig. 1D, the transcript accumulation of all targeted genes, including MPK2, which shares sufficient sequence homology with MPK1, in stembases of silenced plants was reduced at various levels. Furthermore, no apparent altered phenotypes were observed on the silenced plants 15 days after agroinfiltration.

Upon the inoculation of $R$. solanacearum, silencing of MKK2 or MPK1/2 in H7996 resulted in a partial wilting phenotype in some of the assayed plants (Fig. 2B), while silencing of other targeted genes did not cause apparent wilting 12 DPI. However, in most cases, higher proportions of the silenced plants were detected with the presence of the bacterium in stembases and/or mid-stems compared with the controls (Table 2). Consistently, pairwise $t$-test further illustrated that silencing of five (MKK2, MKK4, MPK1, MPK2 and MPK3) of the test genes resulted in significantly increased bacterial proliferation in stembases and/or mid-stems compared with H7996 plants inoculated with the empty vector (Table 2). These results indicated that silencing of MAPK cascades led to reduced the resistance of tomato to BW.

\section{Discussion}

In this study, we used TRV-VIGS approach to systematically uncover whether certain defense signaling pathways play roles in the resistance of tomato to BW. When VIGS is used for functional studies of genes, concerns about the possible suppression of non-targeted genes are often raised as a shortcoming (Baulcombe 1999; Burch-Smith et al. 2004). However, our results (Table 1, Fig. 1, ACO4) along with previous reports (Bhattarai et al. 2007, Ekengren et al. 2003, SenthilKumar et al. 2007, Thomas et al. 2001) suggested that, 
while a stretch of $21-23$ nucleotides with $100 \%$ identity to a targeted mRNA is sufficient to trigger gene silencing, it is frequently insufficient to elicit noteworthy co-silencing of paralogs; longer stretches of identical sequences are required. Therefore, although the possibility that we have co-silenced some other related genes cannot be completely ruled out because of the unavailability of the complete tomato genome sequence, we projected that there would be a considerable level of specificity in our VIGS experiments. Another limitation of VIGS is that it often does not lead to uniform and complete repression of the expression of a targeted gene throughout an infected plant (Burch-Smith et al. 2004, Ekengren et al. 2003). A threshold for effective silencing of each gene to exhibit significant and detectable effects on a specific functional context could be different from others, particularly at the translational and the functional activity levels. Therefore, this study is not aimed at evaluating the importance of individual genes that have been silenced, but at evaluating the involvement of certain pathways in the resistance to $R$. solanacearum, judging from the silencing effect of several genes in the same pathway.

Our study is the first report revealing that the tomato's defense mechanism against BW involves multiple signaling pathways. First, our data together suggested a positive role for the ET response pathway in the resistance of tomato to BW. The ET signaling pathway in plants has been well studied. ACO genes regulate ET biosynthesis, which then inactivates CTR1 (Gao et al. 2003). Inactivation of CTR1 results in de-repression of EIN2 and then activation of ERF1, finally resulting in defense response (Ouaked et al. 2003). Additionally, a Nicotiana benthamiana homolog of ERF3 was shown to induce expression of ERF1 (Nasir et al. 2005). It is known that the ET signaling and response pathway could play a positive or negative role in plant disease defense in different host-pathogen interactions (Lin et al. 2008b, van Loon et al. 2006). Previously, it has been shown that ein2 mutant of the susceptible Arabidopsis ecotype Col0 displayed delayed wilting symptom development compared with the wild-type plant in response to $R$. solanacearum infection (Hernandez-Blanco et al. 2007), suggesting that the ET signaling pathway may play a negative role in Arabidopsis tolerance to R. solanacearum. However, in this study, we showed that silencing of $A C O 1 / 3, E I N 2$ and ERF3 in BWresistant tomato $\mathrm{H} 7996$ caused a significant increase in $R$. solanacearum proliferation, and consistently silencing CTR1 in BW-susceptible tomato L390 led to enhanced tolerance to this bacterium. These results suggested that the ET pathway plays a positive role in the resistance of tomato to BW. Notably, our study on silencing of
COI1 in H7996 suggests that the JA signaling pathway is positively involved in the defense mechanism of tomato against BW (our submitted data). This result also is not in agreement with the report in Arabidopsis (HernandezBlanco et al. 2007), in which coi1 mutant of ecotype Col0 displayed delayed development of BW symptom. Therefore, our findings provide additional support for differences in $R$. solanacearum interactions with tomato and Arabidopsis (Lin et al. 2008a). Additionally and most significantly, our study depicts the nature of resistance mechanisms of solanaceous plants to $R$. solanacearum, although knocking down of the target genes by taking a transgenic RNAi approach would further help fortify these results.

SA-related defense pathway has been well studied in Arabidopsis where NPR1 is required for positively regulating TGA2.2 and TGA1 a to activate the expression of downstream defense genes, resulting in a final defense response. These defense genes, however, are also involved in the cross-communication between SA- and JA-dependent defense signaling pathways (Ndamukong et al. 2007, Thurow et al. 2005). Based on our data, it is suggested that the SA- and JA-related defense pathways are involved in the resistance of tomato against the attack of $R$. solanacearum. In Arabidopsis, previous reports indicated that inactivation of JAand ET-related signaling pathways, but not SA-related pathways, resulted in increased disease development and bacterial proliferation in the susceptible Col ecotype upon $R$. solanacearum infection (Hernandez-Blanco et al. 2007, Hirsch et al. 2002), while the resistance of ecotype $\mathrm{Nd}-1$ was demonstrated to be partially SA dependent (Deslandes et al. 2002). Although the $R$ gene (RRS1) has been isolated from $\mathrm{Nd}-1$ and shown to confer enhanced resistance when over-expressed in Col plants (Deslandes et al. 2002), no direct evidence has been obtained for the association between the SA signaling pathway and the RRS1-mediated resistance. Therefore, it is important to further assess whether the studied tomato genes function in the Solanaceae SA-related signaling pathway similarly as in Arabidopsis by looking into the defense mechanism of tomato. Our study reveals a crucial scope for Solanaceae defense response against this bacterium. Further study on the definite function of these putative SA-related genes in tomato disease response is in progress.

Our study suggested that tomato's defense mechanism against BW involves MAPK cascades. This is the first study suggesting the involvement of MAPK cascades in a plant defense mechanism against a xyleminfecting pathogen. Previous studies have demonstrated that MPK1, MPK2, MPK3 and their orthologs are convergent points in various disease-defense signaling 
networks of solanaceous species after the perception of viral, bacterial, fungal and nematode pathogens by resistance proteins or microbe-associated molecular pattern receptors (Ekengren et al. 2003, Jin et al. 2003, Li et al. 2006, Stulemeijer et al. 2007). In $\mathrm{N}$. benthamiana, these MAPKs are activated by MAPK kinases (MAPKK), such as MEK1 (corresponding to tomato MKK3), MEK2 (corresponding to tomato MKK2) and SIPKK (corresponding to tomato MKK4); MAPKKK $\alpha$ $(M P 3 K \alpha)$ acts as an upstream activator above the MAPKK(del Pozo et al. 2004). In tomato, both MKK2 and MKK4 can phosphorylate MPK2 and MPK3 (Pedley and Martin 2004). In tobacco, NTF6 (corresponding to tomato MPK4) is regulated by MEK1 (corresponding to tomato MKK3) (Calderini et al. 2001, Soyano et al. 2003) and SIPKK (corresponding to tomato MKK4) (Gomi et al. 2005). In this study, however, our data did not support the involvement of MP3K $\alpha$, MKK3 or MPK4 in tomato's defense mechanism against $R$. solanacearum. In this case, an unknown MP3K may be involved in the defense mechanism. Nevertheless, because it is possible that the decreased transcript level of these two genes by VIGS was still sufficient to produce enough functional protein in the silenced plant, we cannot definitively exclude their possible role in tomato's BW defense at this point. Future studies will lead to the identification and confirmation of the components of the MAPK cascades in the BW defense mechanism of tomato.

In nature, plants orchestrate multiple defense signaling pathways to achieve proper response to various pathogen attacks (Pieterse and Dicke 2007). On the basis of our results, we proposed that the resistance of tomato to BW involves, at least, ET-, SA- and MAPK-related signaling pathways. In addition, silencing of COI1 attenuated H7996 resistance to BW (our submitted data), suggesting that the JA signaling pathway is positively involved in tomato's defense mechanism against $R$. solanacearum as well. Hence, JA, ET and SA defense signaling pathways may interact synergistically, rather than antagonistically, in the resistance of tomato against BW. Our study adds to conclusions that JA/ET- and SA-related defense pathways do not always antagonize each other in different combinations of plant and pathogen/pest interactions (Block et al. 2005, Guo and Stotz 2007, Kanneganti et al. 2006, Mur et al. 2006, O'Donnell et al. 2003, Spoel et al. 2007, Thaler et al. 2002). Furthermore, as no case where the level of increased susceptibility to $R$. solanacearum observed in this study was as severe as seen in a susceptible tomato cultivar (Fig. 2B, Table 2), these defense signaling pathways are suggested to interact in an additive mode. Our previous study showed that over-expression of Arabidopsis NPR1, a central regulator of the SA signaling pathway, in a susceptible tomato cultivar did not lead to the full spectrum of H7996 resistance to $R$. solanacearum (Lin et al. 2004), further supporting the suggested additive interplays between these pathways in the overall resistance in tomato. Additionally, silencing of SIPK and/or WIPK resulted in the reduction of JA and thus led to SA accumulation in tobacco (Seo et al. 2007), and co-silencing of tomato MPK1 and MPK2 reduced JA biosynthesis and JAdependent signaling pathway (Kandoth et al., 2007). Moreover, MAPK cascades are suggested to be involved in ET signaling transduction pathway in Arabidopsis (Yoo et al. 2008). Thus, certain interplays between MAPK cascades, JA/ET and SA pathways in the tomato's BW defense network may also exist. How a BW-resistant tomato plant tailors the quantity, composition and timing of a defense signal signature in response to the systemic attack of $R$. solanacearum, which involves orchestration of multiple defense signaling pathways, remains to be investigated further.

Acknowledgements - The authors thank Dr Savithramma Dinesh-Kumar for providing the TRV vectors. Technical assistance by Ms Mei-hong Chuang and advice on statistics from Ms DR Ledesma are highly appreciated. This work was supported by grants from the Council of Agriculture, Republic of China (96AS-1.2.1-ST-a1-15 and 97AS-1.2.1ST-a1-17 to C-P Cheng and J-F Wang), and from National Taiwan University (97R0066-37 to C-P Cheng).

\section{References}

Baulcombe DC (1999) Fast forward genetics based on virus-induced gene silencing. Curr Opin Plant Biol 2: 109-113

Bhattarai KK, Li Q, Liu Y, Dinesh-Kumar SP, Kaloshian I (2007) The MI-1-mediated pest resistance requires Hsp90 and Sgt1. Plant Physiol 144: 312-23

Block A, Schmelz E, O’Donnell PJ, Jones JB, Klee HJ (2005) Systemic acquired tolerance to virulent bacterial pathogens in tomato. Plant Physiol 138: 1481-1490

Bostock RM (2005) Signal crosstalk and induced resistance: straddling the line between cost and benefit. Annu Rev Phytopathol 43: 545-580

Burch-Smith TM, Anderson JC, Martin GB, Dinesh-Kumar SP (2004) Applications and advantages of virus-induced gene silencing for gene function studies in plants. Plant J 39: $734-746$

Calderini O, Glab N, Bergounioux C, Heberle-Bors E, Wilson C (2001) A novel tobacco mitogen-activated protein (MAP) kinase kinase, NtMEK1, activates the cell cycle-regulated p43 ${ }^{\mathrm{Ntf6}}$ MAP kinase. J Biol Chem 276: 18139-18145 
Carmeille A, Caranta C, Dintinger J, Prior P, Luisetti J, Besse P (2006) Identification of QTLs for Ralstonia solanacearum race 3-phylotype II resistance in tomato. Theor Appl Genet 113: 110-121

Deslandes L, Olivier J, Theulieres F, Hirsch J, Feng DX, Bittner-Eddy P, Beynon J, Marco Y (2002) Resistance to Ralstonia solanacearum in Arabidopsis thaliana is conferred by the recessive $R R S 1-R$ gene, a member of a novel family of resistance genes. Proc Natl Acad Sci USA 99: 2404-2409

Deslandes L, Olivier J, Peeters N, Feng DX, Khounlotham M, Boucher C, Somssich I, Genin S, Marco Y (2003) Physical interaction between RRS1-R, a protein conferring resistance to bacterial wilt, and PopP2, a type III effector targeted to the plant nucleus. Proc Natl Acad Sci USA 100: 8024-8029

Ekengren SK, Liu Y, Schiff M, Dinesh-Kumar SP, Martin GB (2003) Two MAPK cascades, NPR1, and TGA transcription factors play a role in Pto-mediated disease resistance in tomato. Plant J 36: 905-917

Gao Z, Chen YF, Randlett MD, Zhao XC, Findell JL, Kieber J, Schaller GE (2003) Localization of the Raf-like kinase CTR1 to the endoplasmic reticulum of Arabidopsis through participation in ethylene receptor signaling complexes. J Biol Chem 278: 34725-34732

Grimault V, Anais G, Prior P (1994) Distribution of Pseudomonas solanacearum in the stem tissues of tomato plants with different levels of resistance to bacterial wilt. Plant Pathol 43: 663-668

Gomi K, Ogawa D, Katou S, Kamada H, Nakajima N, Saji H, Soyano T, Sasabe M, Machida Y, Mitsuhara I, Ohashi $Y$, Seo S (2005) A mitogen-activated protein kinase NtMPK4 activated by SIPKK is required for jasmonic acid signaling and involved in ozone tolerance via stomatal movement in tobacco. Plant Cell Physiol 46: $1902-1914$

Guo X, Stotz HU (2007) Defense against Sclerotinia sclerotiorum in Arabidopsis is dependent on jasmonic acid, salicylic acid, and ethylene signaling. Mol Plant Microbe Interact 20: 1384-1395

Hernandez-Blanco C, Feng DX, Hu J, Sanchez-Vallet A, Deslandes L, Llorente F, Berrocal-Lobo M, Keller H, Barlet X, Sanchez-Rodriguez C, Anderson LK, Somerville S, Marco Y, Molina A (2007) Impairment of cellulose synthases required for Arabidopsis secondary cell wall formation enhances disease resistance. Plant Cell 19: 890-903

Hirsch J, Deslandes L, Feng DX, Balague C, Marco Y (2002) Delayed symptom development in ein2-1, an Arabidopsis ethylene-insensitive mutant, in response to bacterial wilt caused by Ralstonia solanacearum. Phytopathology 92: 1142-1148

Jin H, Liu Y, Yang KY, Kim CY, Baker B, Zhang S (2003) Function of a mitogen-activated protein kinase pathway in $N$ gene-mediated resistance in tobacco. Plant J 33: 719-731

Kandoth PK, Ranf S, Pancholi SS, Jayanty S, Walla MD, Miller W, Howe GA, Lincoln DE, Stratmann JW (2007) Tomato MAPKs LeMPK1, LeMPK2, and LeMPK3 function in the systemin-mediated defense response against herbivorous insects. Proc Natl Acad Sci USA 104: 12205-12210

Kanneganti TD, Huitema E, Cakir C, Kamoun S (2006) Synergistic interactions of the plant cell death pathways induced by Phytophthora infestans Nepl-like protein PiNPP1.1 and INF1 elicitin. Mol Plant Microbe Interact 19: $854-863$

Koornneef A, Pieterse CM (2008) Cross talk in defense signaling. Plant Physiol 146: 839-844

Lahaye T (2004) Illuminating the molecular basis of gene-for-gene resistance; Arabidopsis thaliana RRS1- $R$ and its interaction with Ralstonia solanacearum popP2. Trends Plant Sci 9: 1-4

Li Q, Xie QG, Smith-Becker J, Navarre DA, Kaloshian I (2006) Mi-1-Mediated aphid resistance involves salicylic acid and mitogen-activated protein kinase signaling cascades. Mol Plant Microbe Interact 19: 655-664

Lin WC, Lu CF, Wu JW, Cheng ML, Lin YM, Yang NS, Black L, Green SK, Wang JF, Cheng CP (2004) Transgenic tomato plants expressing the Arabidopsis NPR1 gene display enhanced resistance to a spectrum of fungal and bacterial diseases. Transgenic Res 13: $567-581$

Lin YM, Chou IC, Wang JF, Ho FI, Chu YJ, Huang PC, Lu DK, Shen HL, Elbaz M, Huang SM, Cheng CP (2008a) Transposon mutagenesis reveals differential pathogenesis of Ralstonia solanacearum on tomato and Arabidopsis. Mol Plant Microbe Interact 21: $1261-1270$

Lin Z, Alexander L, Hackett R, Grierson D (2008b) LeCTR2, a CTR1-like protein kinase from tomato, plays a role in ethylene signalling, development and defence. Plant J 54: 1083-1093

Liu Y, Schiff M, Dinesh-Kumar SP (2002) Virus-induced gene silencing in tomato. Plant J 31: 777-786

van Loon LC, Rep M, Pieterse CM (2006) Significance of inducible defense-related proteins in infected plants. Annu Rev Phytopathol 44: 135-162

Mur LA, Carver TL, Prats E (2006) NO way to live; the various roles of nitric oxide in plant-pathogen interactions. J Exp Bot 57: 489-505

Nakaho K, Inoue H, Takayama T, Miyagawa H (2004) Distribution and multiplication of Ralstonia solanacearum in tomato plants with resistance derived from different origins. J Gen Plant Pathol 70: 115-119

Nasir KH, Takahashi Y, Ito A, Saitoh H, Matsumura H, Kanzaki H, Shimizu T, Ito M, Fujisawa S, Sharma PC, Ohme-Takagi M, Kamoun S, Terauchi R (2005) 
High-throughput in planta expression screening identifies a class II ethylene-responsive element binding factor-like protein that regulates plant cell death and non-host resistance. Plant J 43: 491-505

Ndamukong I, Abdallat AA, Thurow C, Fode B, Zander M, Weigel R, Gatz C (2007) SA-inducible Arabidopsis glutaredoxin interacts with TGA factors and suppresses JA-responsive PDF1.2 transcription. Plant J 50: 128-139

O'Donnell PJ, Schmelz E, Block A, Miersch O, Wasternack C, Jones JB, Klee HJ (2003) Multiple hormones act sequentially to mediate a susceptible tomato pathogen defense response. Plant Physiol 133: 1181-1189

Ouaked F, Rozhon W, Lecourieux D, Hirt H (2003) A MAPK pathway mediates ethylene signaling in plants. EMBO J 22: 1282-1288

Pedley KF, Martin GB (2004) Identification of MAPKs and their possible MAPK kinase activators involved in the Pto-mediated defense response of tomato. J Biol Chem 279: 49229-49235

Pieterse CM, Dicke M (2007) Plant interactions with microbes and insects: from molecular mechanisms to ecology. Trends Plant Sci 12: 564-569

del Pozo O, Pedley KF, Martin GB (2004) MAPKKKalpha is a positive regulator of cell death associated with both plant immunity and disease. EMBO J 23: 3072-3082

Prior P, Grimault V, Schmit J (1994) Resistance to bacterial wilt (Pseudomonas solanacearum) in tomato: present status and prospects. In: Hayward AC, Hartman GL (eds) Bacterial Wilt: The Disease and Its Causative Agent, Pseudomonas solanacearum. CAB International, Wallingford, pp 209-223

Robatzek S, Bittel P, Chinchilla D, Kochner P, Felix G, Shiu SH, Boller T (2007) Molecular identification and characterization of the tomato flagellin receptor LeFLS2, an orthologue of Arabidopsis FLS2 exhibiting characteristically different perception specificities. Plant Mol Biol 64: 539-547

Scott JW, Wang JF, Hanson PM (2005) Breeding tomatoes for resistance to bacterial wilt, a global view. In: Momol $\mathrm{T}$, Ji $\mathrm{P}$, Jones JB (eds) Proceeding of $1 \mathrm{st}$ International Symposium on Tomato Diseases. Acta Horticulturae, Florida, USA, pp 161-172

Senthil-Kumar M, Hema R, Anand A, Kang L, Udayakumar M, Mysore KS (2007) A systematic study to determine the extent of gene silencing in Nicotiana benthamiana and other Solanaceae species when heterologous gene sequences are used for virus-induced gene silencing. New Phytol 176: 782-791

Seo S, Katou S, Seto H, Gomi K, Ohashi Y (2007) The mitogen-activated protein kinases WIPK and SIPK regulate the levels of jasmonic and salicylic acids in wounded tobacco plants. Plant J 49: 899-909

Soyano T, Nishihama R, Morikiyo K, Ishikawa M, Machida $\mathrm{Y}(2003) \mathrm{NQK} 1 / \mathrm{NtMEK} 1$ is a MAPKK that acts in the
NPK1 MAPKKK-mediated MAPK cascade and is required for plant cytokinesis. Genes Dev 17: 1055-1067

Spoel SH, Johnson JS, Dong X (2007) Regulation of tradeoffs between plant defenses against pathogens with different lifestyles. Proc Natl Acad Sci USA 104: 18842-18847

Stulemeijer IJ, Stratmann JW, Joosten MH (2007) Tomato mitogen-activated protein kinases LeMPK1, LeMPK2, and LeMPK3 are activated during the Cf-4/Avr4-induced hypersensitive response and have distinct phosphorylation specificities. Plant Physiol 144: 1481-1494

Thaler JS, Fidantsef AL, Bostock RM (2002) Antagonism between jasmonate- and salicylate-mediated induced plant resistance: effects of concentration and timing of elicitation on defense-related proteins, herbivore, and pathogen performance in tomato. J Chem Ecol 28: $1131-1159$

Thomas CL, Jones L, Baulcombe DC, Maule AJ (2001) Size constraints for targeting post-transcriptional gene silencing and for RNA-directed methylation in Nicotiana benthamiana using a potato virus $X$ vector. Plant J 25: 417-425

Thurow C, Schiermeyer A, Krawczyk S, Butterbrodt T, Nickolov K, Gatz C (2005) Tobacco bZIP transcription factor TGA2.2 and related factor TGA2.1 have distinct roles in plant defense responses and plant development. Plant J 44: 100-113

Vasse J, Danoun S, Trigalet A (2005) Microscopic studies of root infection in resistant tomato cv. Hawaii7996. In: Allen C, Hayward AC (eds) Bacterial Wilt Disease and the Ralstonia solanacearum Species Complex. APS Press, St Paul, MN, pp 285-291

Wang JF, Lin CH (2005) Colonization capacity of Ralstonia solanacearum tomato strains differing in aggressiveness on tomatoes and weeds. In: Allen C, Prior P, Hayward AC (eds) Bacterial Wilt Disease and the Ralstonia solanacearum Species Complex. APS, St Paul, Germany, pp $73-79$

Wang JF, Hanson PM, Bames JA (1998) Worldwide evaluation of an international set of resistance sources to bacterial wilt in tomato. In: Prior P, Allen C, Elphinstone J (eds) Bacterial Wilt Disease: Molecular and Ecological Aspects. Springer-Verlog, Germany, pp $269-275$

Wang JF, Olivier J, Thoquet P, Mangin B, Sauviac L, Grimsley NH (2000) Resistance of tomato line Hawaii7996 to Ralstonia solanacearum Pss4 in Taiwan is controlled mainly by a major strain-specific locus. Mol Plant Microbe Interact 13: 6-13

Wei CF, Kvitko BH, Shimizu R, Crabill E, Alfano JR, Lin NC, Martin GB, Huang HC, Collmer A (2007) A Pseudomonas syringae pv. tomato DC3000 mutant lacking the type III effector HopQ1-1 is able to cause 
disease in the model plant Nicotiana benthamiana. Plant J 51: 32-46

Yoo SD, Cho YH, Tena G, Xiong Y, Sheen J (2008) Dual control of nuclear EIN3 by bifurcate MAPK cascades in $\mathrm{C}_{2} \mathrm{H}_{4}$ signaling. Nature 451: 789-795

\section{Supporting information}

Additional Supporting Information may be found in the online version of this article:
Appendix S1. Primers used to amplify candidate genes from tomato $\mathrm{H} 7996$ and in RT-PCR analyses to evaluate transcript level of silenced genes. N/A, not applicable.

Please note: Wiley-Blackwell are not responsible for the content or functionality of any supporting materials supplied by the authors. Any queries (other than missing material) should be directed to the corresponding author for the article. 